\title{
Celebrating 80 years of the Permanent Service for Mean Sea Level (PSMSL)
}

\author{
LESLEY RICKARDS ${ }^{1,2}$, ANDREW MATTHEWS ${ }^{1}$, KATHLEEN GORDON ${ }^{1}$, \\ MARK TAMISEA ${ }^{1}$, SVETLANA JEVREJEVA ${ }^{1}$, PHILIP WOODWORTH ${ }^{1}$ \& \\ ELIZABETH BRADSHAW ${ }^{2}$ \\ 1 Permanent Service for Mean Sea Level (PSMSL), National Oceanography Centre, Joseph Proudman Building, \\ 6 Brownlow Street, Liverpool L3 5DA, UK \\ 1jr@bodc.ac.uk \\ 2 British Oceanographic Data Centre, Joseph Proudman Building, 6 Brownlow Street, Liverpool L3 5DA, UK
}

\begin{abstract}
The PSMSL was established as a "Permanent Service" of the International Council for Science in 1958, but in practice was a continuation of the Mean Sea Level Committee which had been set up at the Lisbon International Union of Geodesy and Geophysics (IUGG) conference in 1933. Now in its 80th year, the PSMSL continues to be the internationally recognised databank for long-term sea level change information from tide gauge records. The PSMSL dataset consists of over 2100 mean sea level records from across the globe, the longest of which date back to the start of the 19th century. Where possible, all data in a series are provided to a common benchmark-controlled datum, thus providing a record suitable for use in time series analysis. The PSMSL dataset is freely available for all to use, and is accessible through the PSMSL website (www.psmsl.org).
\end{abstract}

Key words sea level; observing system; data; data centre

\section{INTRODUCTION}

Since 1933, the Permanent Service for Mean Sea Level (PSMSL) has operated at the National Oceanography Centre (NOC), Liverpool (previously the Proudman Oceanographic Laboratory), with the aims of providing the global data bank for long-term sea level information from tide gauges, and of providing a wider service to the sea level community. It was a member of the Federation of Astronomical and Geophysical Data Analysis Services (FAGS) until its dissolution, and works under the auspices of the International Council for Science (ICSU) and is applying for membership of the new ICSU World Data System (WDS).

The dataset and ancillary information are provided free of charge and are made available to the international scientific community through the PSMSL website. The metadata includes descriptions of benchmarks and their locations, types of instrumentation and frequency of data collection (where available), as well as notes on other issues that we feel the users should be aware of (e.g. earthquakes that are known to have occurred in the vicinity or subsidence due to local groundwater extraction). The free access to data by users is central to the PSMSL's mission, and conversely no supplier is ever paid for their data, nor are licensing terms ever entered into.

\section{PSMSL-RELATED SCIENTIFIC MEETINGS, ACTIVITIES AND EVENTS}

PSMSL staff have continued to be active participants in the IOC Group of Experts on the Global Sea Level Observing System (GLOSS) and GGOS meetings, co-convened sea level sessions at the EGU and contributed to IOC coordination group tsunami warning system meetings. PSMSL has contributed to the IPCC Fifth Assessment Report with Dr Svetlana Jevrejeva a lead author for Working Group I, Prof. Philip Woodworth a review editor and other PSMSL staff also contributing.

2013 marked the 80th anniversary of the foundation of the PSMSL. To commemorate this PSMSL hosted or co-convened the following events:

- A workshop in Liverpool, UK, on major research topics in sea level science. The workshop, held in October 2013, included talks reviewing aspects of the IPCC Fifth Assessment Report (Working Group I). There were also presentations covering many aspects of regional variability in sea level. 
- A symposium entitled "Implications of sea level change for the coastal zone - a symposium to mark the 80th anniversary of the Permanent Service for Mean Sea Level (PSMSL)" at the IAHS/IAPSO/IASPEI Joint Assembly in Gothenburg, Sweden (July 2013).

- A session at EGU 2013: Global and regional sea level rise and variability: from past to future (April 2013).

\section{COLLECTION, ANALYSIS, PUBLICATION AND INTERPRETATION OF MONTHLY AND ANNUAL MEANS OF SEA LEVEL FROM THE GLOBAL NETWORK OF TIDE GAUGES}

Since the start of 2012, approximately 25283 station-months of MSL data from about 830 stations were added to the PSMSL databank (and a further 2113 months were updated) (Fig. 1), bringing the total PSMSL data holdings to over 716301 station-months from 2170 stations. Most of the data originated from Europe and North America together with significant datasets from Japan and Australia (Fig. 2). There are gaps in data receipts from parts of Southeast Asia, central and South America; these are presently being targeted to try to improve data flow. Africa continues to receive special attention through ODINAfrica and IOTWS, although data flow has improved considerably over the last decade. Close links have been maintained with the University of Hawaii Sea Level Center and other international sea level data centres.
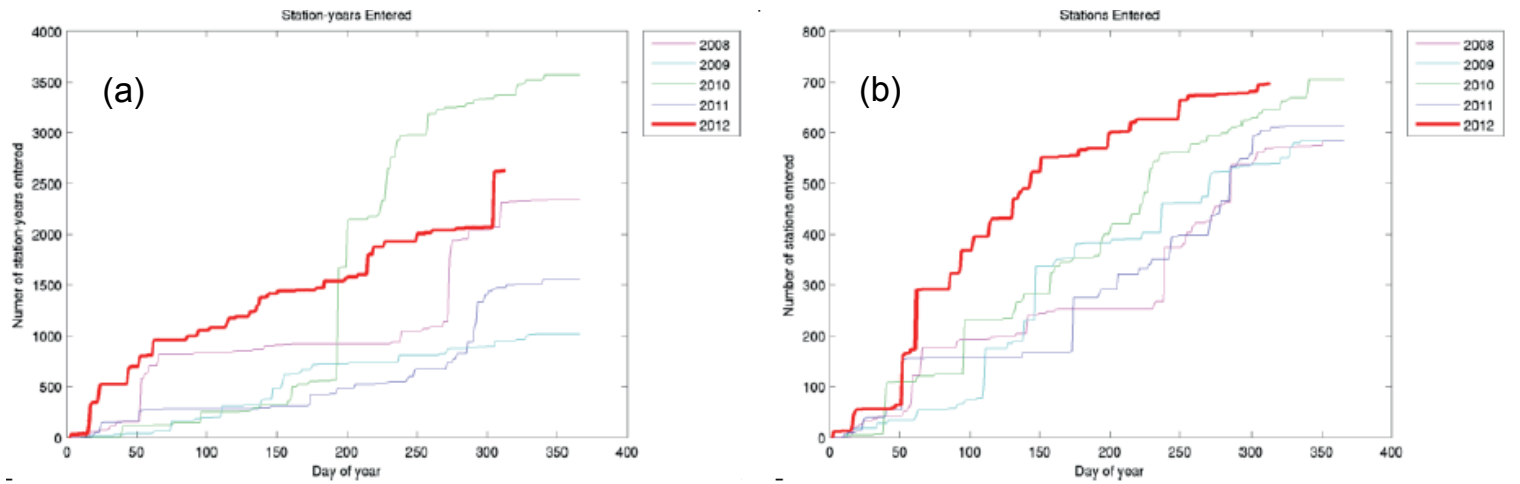

Fig. 1 (a) Number of station years added to PSMSL database in 2012, (b) number of stations with data added to PSMSL database in 2012.

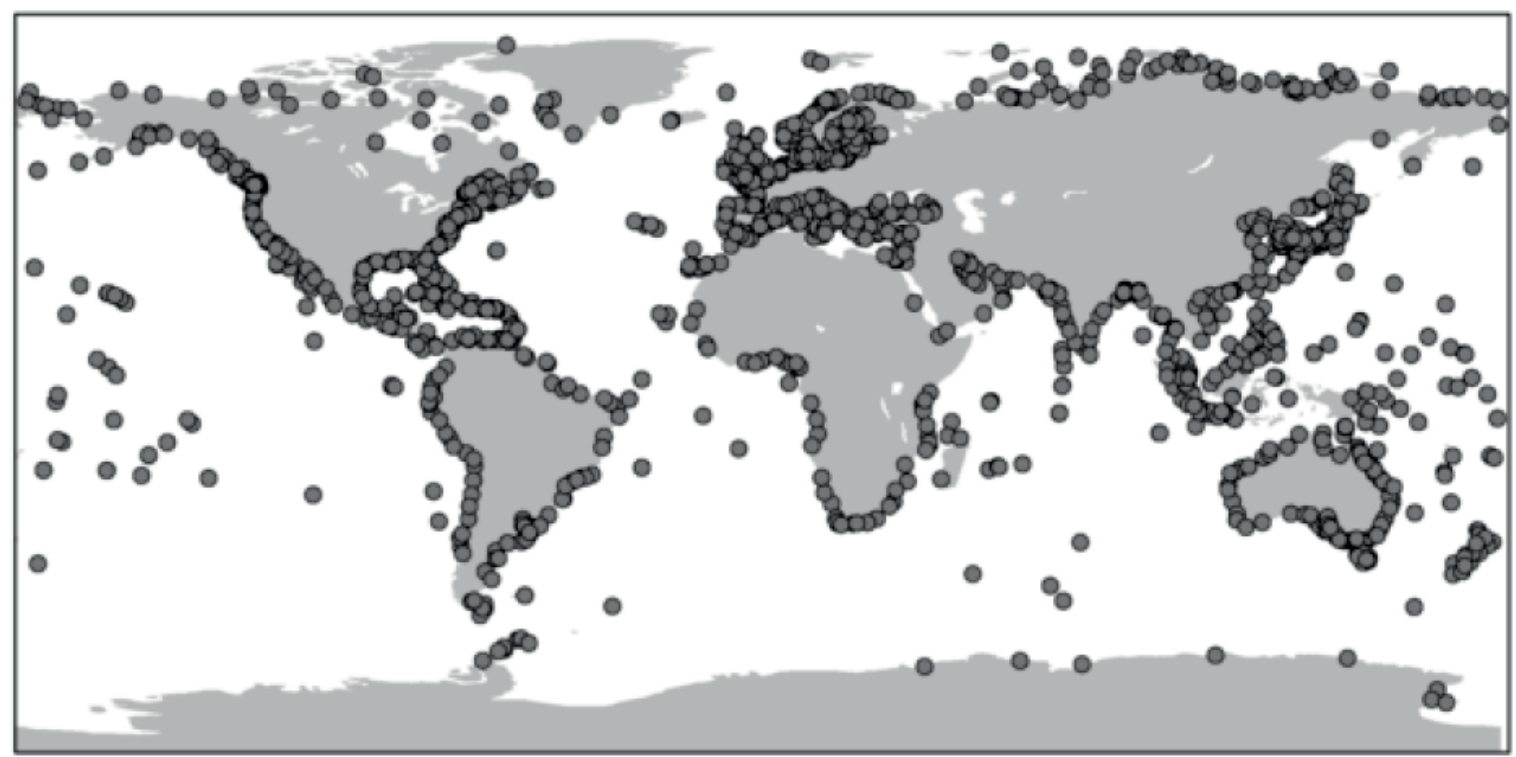

Fig. 2 Distribution of all PSMSL stations, both research quality (RLR) and non-datum controlled stations (known as "Metric only"). 


\section{Interactive map showing long-term trends}

The relative sea level trends map allows interactive investigation of global mean sea level trends since 1900 (Fig. 3). The limits of the period to be viewed can be selected by either moving the buttons on the slider or by entering the values in the two text boxes. A period of at least 30 years must be selected. The map will display the annual sea level trend at each station that has suitable data available over the selected period. Further information is available on the Methods page (see http://www.psmsl.org/products/trends/methods.php).

Note that these measured trends are not corrected for local land movement. Furthermore, no attempt has been made to assess the validity of any individual fit, so results should not be treated as a publication quality value suitable for use in planning or policy making.

The map should be used with some care as anomalous trends have many causes:

- land movements (e.g. earthquakes, glacial isostatic adjustment)

- unexplained instrumental datum shifts

- changes in atmospheric pressure

- short records.

A more complete account can be found in the geophysical signals section of the PSMSL website (see http://www.psmsl.org/train and info/geo signals/). A table of long-term trends derived from annual mean values of sea level in the PSMSL RLR dataset demonstrates the rate of change of sea level at each station.

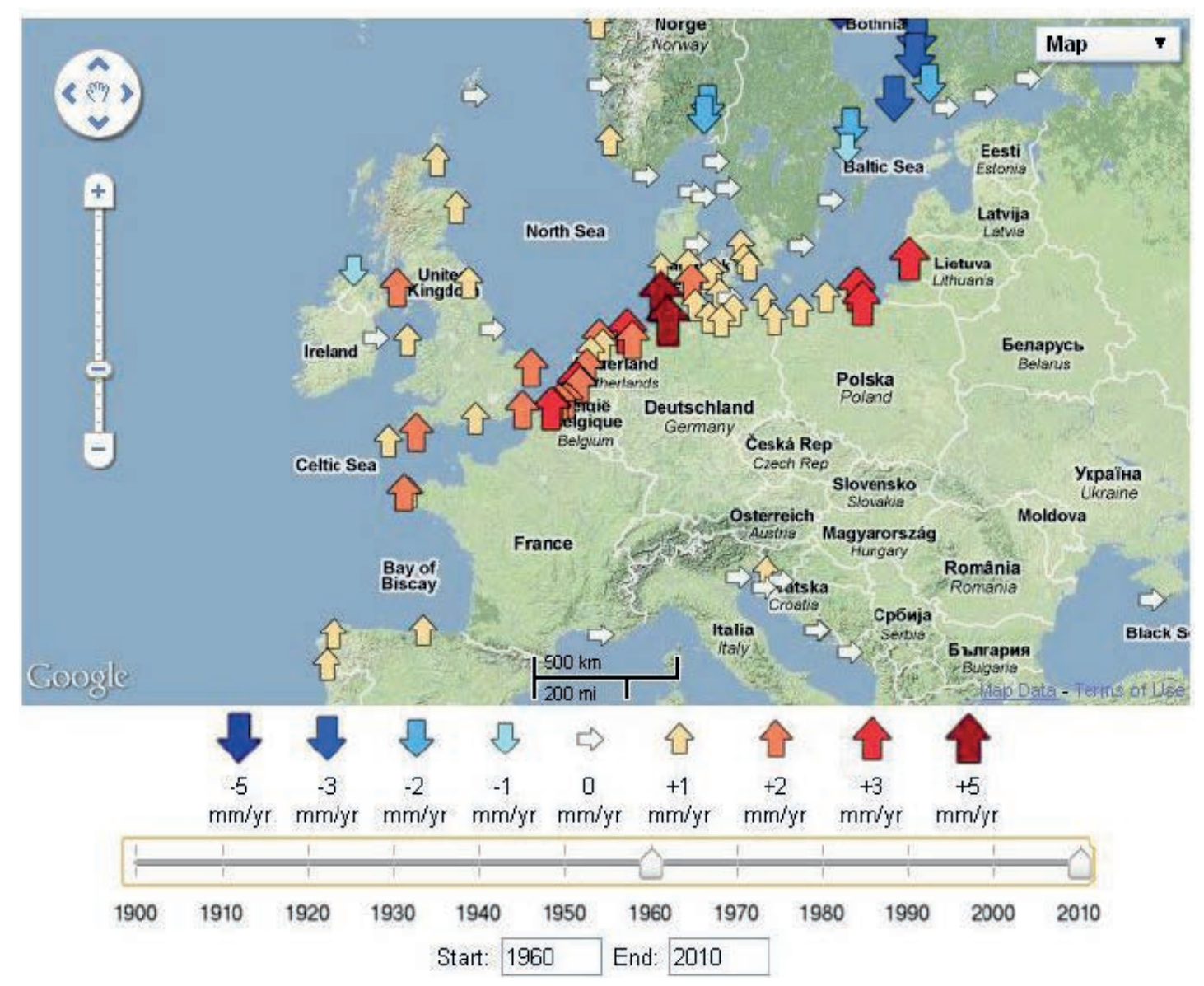

Fig. 3 Sample map showing relative sea level trends. 


\section{Interactive map showing sea level anomalies}

Annual mean sea level can vary considerably from year to year in response to various meteorological and oceanographic forcings, typically by hundreds of millimetres. The product allows one to examine the global variations in a year of your choice, selecting this year using either the slider or the text box. The map presents the difference between the annual RLR data for each station (which is quality and datum controlled) compared to that station's long-term mean over the baseline period of 1960-1990.

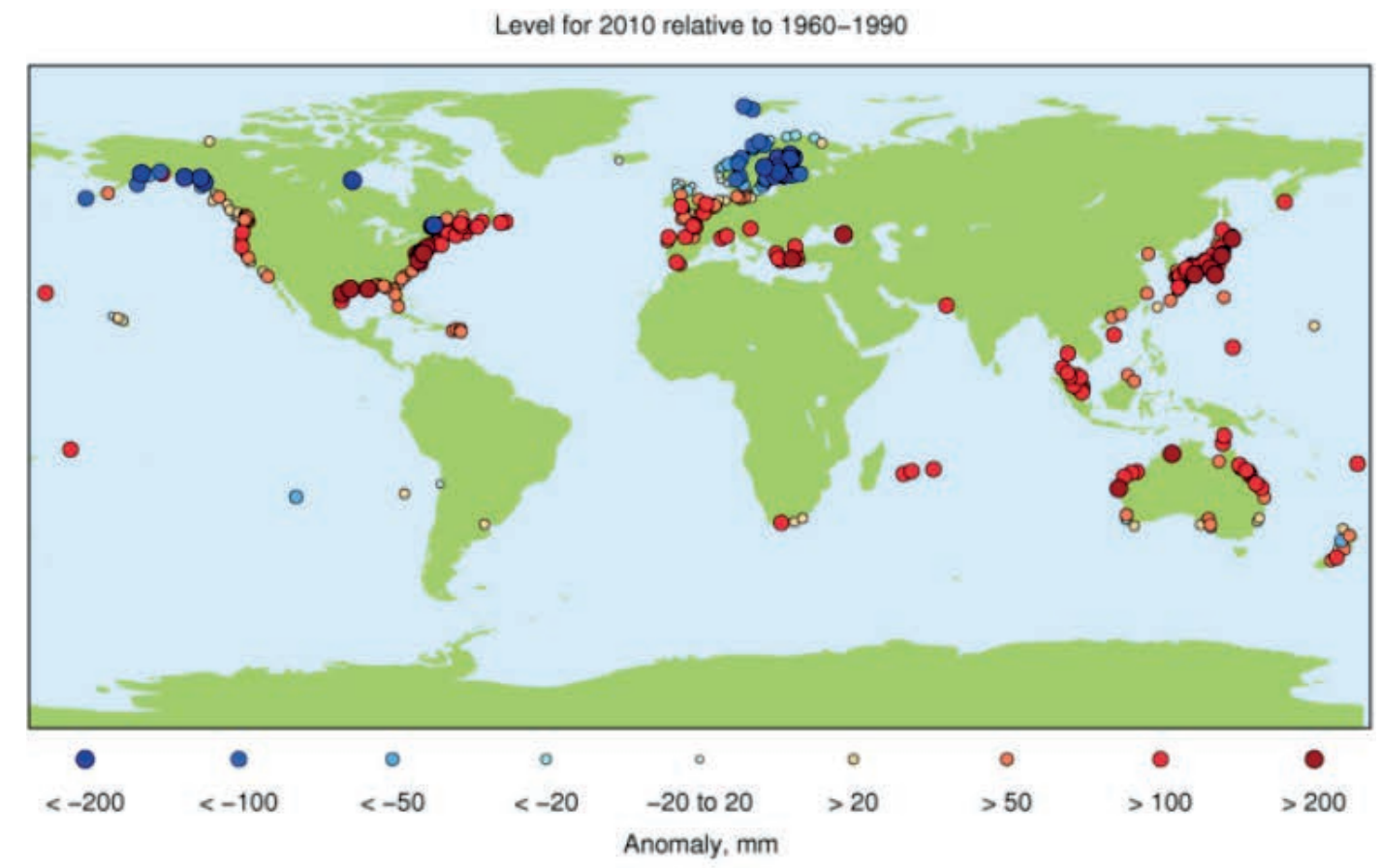

Level for 2010 relative to $1960-1990$ (detrended)

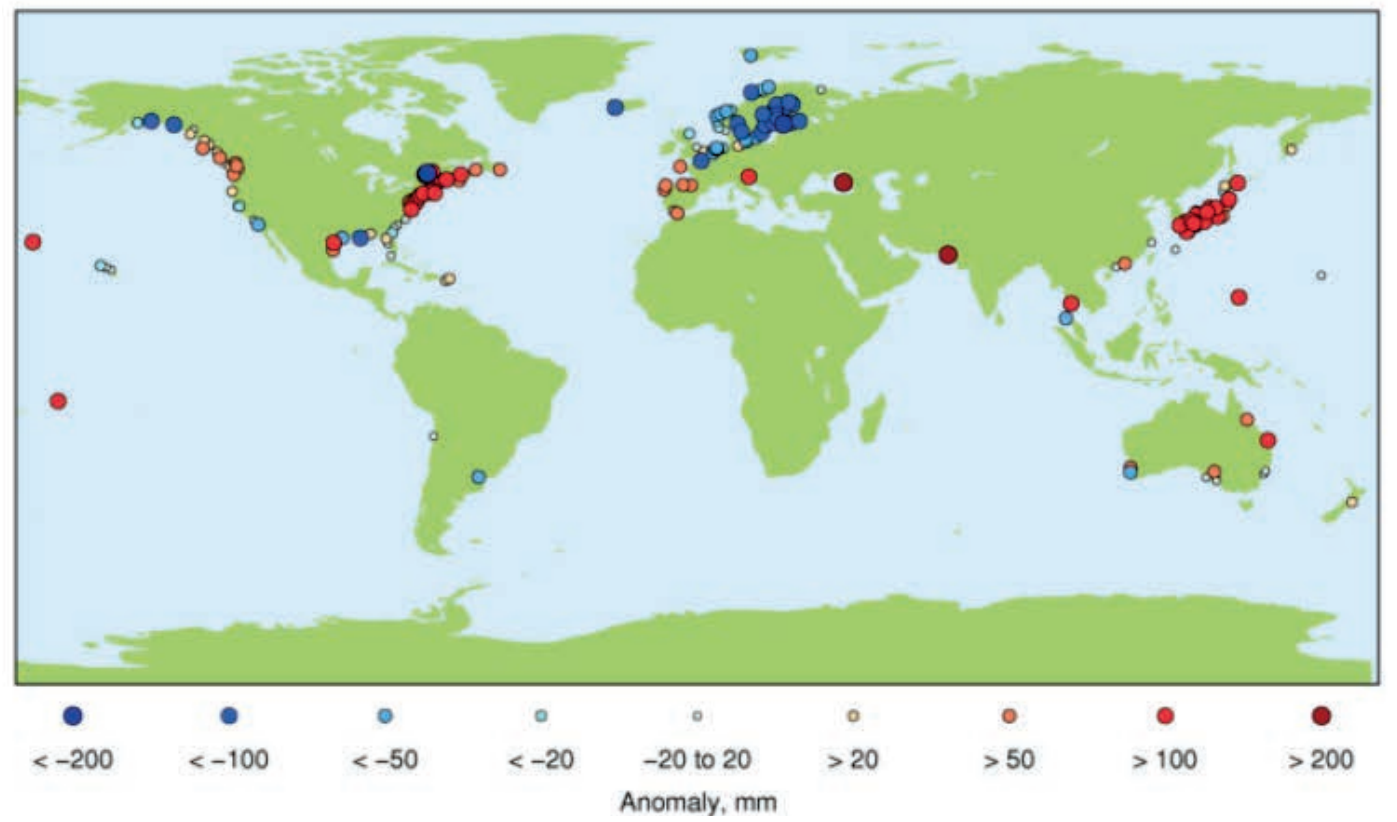

Fig. 4 Sea level anomalies for 2010 relative to 1960-1990. (Top image: not detrended. Bottom image: detrended.) 
The long-term trend at each station (estimated using the baseline period) can be removed if required. This will prevent results being dominated by long-term changes, but will result in the loss of stations for which there is not enough data to calculate a trend. Further information is provided on the methods and derived trends pages of the PSMSL website.

\section{SUMMARY AND FORWARD LOOK}

It can be seen that PSMSL continues to be active with regard to workshops/conferences and with data acquisition and analysis. The functions provided by the PSMSL are in as much demand as ever and new products continue to be developed. Future plans include:

- Improved integration of the mean sea level dataset with higher frequency data and improving the quality of accompanying metadata;

- Keeping contact with data suppliers (the trend being to acquire data from websites rather than direct supply) and ensuring that data made available in real-time are also contributed to PSMSL;

- Inclusion of information on uncertainties/errors in the tide gauge data;

- Addition of a bottom pressure record section and data to the PSMSL website;

- Redevelopment of capacity building/training material.

Acknowledgements Particular thanks as usual go to PSMSL staff and to colleagues at the National Oceanography Centre and British Oceanographic Data Centre who contribute part of their time to PSMSL activities.

\section{REFERENCES}

Holgate, S. J. et al. (2013) New data systems and products at the Permanent Service for Mean Sea Level. Journal of Coastal Research 29(3) 493-504.

IOC (2012) Global Sea Level Observing System (GLOSS) Implementation Plan - 2012. UNESCO/IOC, 41pp. 2012. (IOC Technical Series No.100) (English). 